\title{
Tetraplegia associated with post-operative syringomyelia in spinal tuberculosis: a result of an epidural compartment syndrome?
}

\author{
Nishit Bhatnagar $\mathbb{D}^{1} \cdot$ Ankit Kataria $^{2} \cdot$ Purushotham Lingaiah $^{3} \cdot$ Yugal Karkhur $^{4}$
}

Received: 9 November 2018 / Revised: 6 January 2019 / Accepted: 13 January 2019

(c) International Spinal Cord Society 2019

\begin{abstract}
Introduction The commonly recognized causes of post-operative neurological deterioration in spinal tuberculosis are inadequate decompression, damage to vascular supply of the spinal cord, and multi-drug resistant organisms. There are no known cases of syringomyelia developing after surgical decompression of spinal tuberculosis.

Case presentation A teenage girl presented with rapid onset quadriparesis secondary to a tubercular epidural abscess extending from C4-T8. The neurological status deteriorated to quadriplegia immediately following decompression by hemilaminectomy at C7 and T7 levels. Investigations into the cause of neurological deterioration revealed syrinx formation at T5-9 levels. The patient had partial motor and sensory recovery in the first 3 weeks post-operatively. Tubercular infection was treated with a 1-year course of multi-drug anti-tubercular therapy. However, there was no further neurological improvement at 2 years follow-up.

Discussion Syringomyelia in tuberculosis has been associated with tubercular meningitis, intradural tuberculomas, and postsurgical vascular insult. None of these were implicated as the cause of syrinx formation in this case. We hypothesize that the rapid evolution of epidural abscess in an intact vertebral column led to an acute "epidural compartment syndrome", which caused ischemic damage to the spinal cord. Compression caused by the epidural abscess was relieved by surgical decompression, allowing the central canal to dilate and expand into the softened spinal parenchyma, hence leading to syrinx formation.
\end{abstract}

\section{Introduction}

One-fifth of the global burden of tuberculosis is estimated to be in India, with an incidence of 36 new cases per 100,000 of population per year [1]. Vertebral involvement is seen in around $1 \%$ of tubercular patients. Significant neurological deficit is found in approximately half of the patients with vertebral tuberculosis [2]. For such patients, surgical spinal

Nishit Bhatnagar

nishitbhatnagar@yahoo.co.in

1 Department of Orthopaedics, Lilavati Hospital and Research Center, Mumbai, Maharashtra, India

2 Department of Orthopaedics, Maulana Azad Medical College and Lok Nayak Hospital, New Delhi, India

3 Department of Orthopaedics, Sparsh Hospital, Bengaluru, Karnataka, India

4 Department of Orthopaedics, Max Smart Super Specialty Hospital, New Delhi, India decompression along with anti-tubercular drug therapy is the usual mode of management. However, lack of neurological recovery or even further neurological deterioration can occur in around $10 \%$ of such patients after surgical spinal decompression [3]. Neurological deterioration in these patients can be due to inadequate decompression, multi-drug resistant organisms, physical damage to the spinal cord, or damage to the vascular supply of the spinal cord. To the authors' knowledge this is the first reported case of syringomyelia as a cause of post-operative neurological deterioration following surgical decompression of spinal tuberculosis. A written informed consent was obtained from the parents of the patient for print and electronic publication of this article and the use of clinical photographs.

\section{Case presentation}

A 13-year-old girl, eldest of three children of a daily wage laborer, presented to us with a 1 week history of pain in the 
Table 1 Summary of neurological status before and after the decompressive surgery based on the International Standards for Neurological Classification of Spinal Cord Injuries [4]

\begin{tabular}{|c|c|c|c|c|c|c|c|c|}
\hline \multirow[t]{2}{*}{$\begin{array}{l}\text { Neurological } \\
\text { assessment }\end{array}$} & \multicolumn{2}{|c|}{$\begin{array}{l}\text { Pre- } \\
\text { operative }\end{array}$} & \multicolumn{2}{|c|}{$\begin{array}{l}\text { Immediate } \\
\text { Post-operative }\end{array}$} & \multicolumn{2}{|c|}{$\begin{array}{l}3 \text { days Post- } \\
\text { operative }\end{array}$} & \multicolumn{2}{|c|}{$\begin{array}{l}2 \text { years Post- } \\
\text { operative }\end{array}$} \\
\hline & Right & Left & Right & Left & Right & Left & Right & Left \\
\hline \multicolumn{9}{|l|}{ Motor } \\
\hline C5 & 5 & 5 & 5 & 5 & 5 & 5 & 5 & 5 \\
\hline C6 & 5 & 5 & 0 & 0 & 0 & 3 & 0 & 3 \\
\hline C7 & 0 & 0 & 0 & 0 & 0 & 2 & 0 & 2 \\
\hline $\mathrm{C} 8$ & 0 & 0 & 0 & 0 & 0 & 0 & 0 & 0 \\
\hline $\mathrm{T} 1$ & 0 & 0 & 0 & 0 & 0 & 0 & 0 & 0 \\
\hline L2 & 2 & 2 & 0 & 0 & 0 & 0 & 0 & 0 \\
\hline L3 & 2 & 2 & 0 & 0 & 0 & 0 & 0 & 0 \\
\hline L4 & 2 & 2 & 0 & 0 & 0 & 0 & 0 & 0 \\
\hline L5 & 2 & 2 & 0 & 0 & 0 & 0 & 0 & 0 \\
\hline S1 & 2 & 2 & 0 & 0 & 0 & 0 & 0 & 0 \\
\hline \multicolumn{9}{|l|}{$\begin{array}{l}\text { Sensory light } \\
\text { touch }\end{array}$} \\
\hline $\mathrm{C} 2$ to $\mathrm{C} 6$ & 2 & 2 & 2 & 2 & 2 & 2 & 2 & 2 \\
\hline C7 & 1 & 1 & 0 & 0 & 2 & 2 & 2 & 2 \\
\hline $\mathrm{C} 8$ & 1 & 1 & 0 & 0 & 2 & 2 & 2 & 2 \\
\hline $\mathrm{T} 1$ & 1 & 1 & 0 & 0 & 2 & 2 & 2 & 2 \\
\hline $\mathrm{T} 2$ & 1 & 1 & 0 & 0 & 2 & 2 & 2 & 2 \\
\hline T3 & 1 & 1 & 0 & 0 & 2 & 2 & 2 & 2 \\
\hline $\mathrm{T} 4$ & 1 & 1 & 0 & 0 & 0 & 0 & 0 & 0 \\
\hline T5 & 1 & 1 & 0 & 0 & 0 & 0 & 0 & 0 \\
\hline T6 & 1 & 1 & 0 & 0 & 0 & 0 & 0 & 0 \\
\hline $\mathrm{T} 7$ & 1 & 1 & 0 & 0 & 0 & 0 & 0 & 0 \\
\hline $\mathrm{T} 8$ & 1 & 1 & 0 & 0 & 0 & 0 & 0 & 0 \\
\hline T9onwards & 0 & 0 & 0 & 0 & 0 & 0 & 0 & 0 \\
\hline \multicolumn{9}{|l|}{$\begin{array}{l}\text { Sensory pin } \\
\text { prick }\end{array}$} \\
\hline $\mathrm{C} 2$ to $\mathrm{C} 6$ & 2 & 2 & 2 & 2 & 2 & 2 & 2 & 2 \\
\hline C7 & 1 & 1 & 0 & 0 & 1 & 1 & 1 & 1 \\
\hline $\mathrm{C} 8$ & 1 & 1 & 0 & 0 & 1 & 1 & 1 & 1 \\
\hline $\mathrm{T} 1$ & 1 & 1 & 0 & 0 & 1 & 1 & 1 & 1 \\
\hline $\mathrm{T} 2$ & 1 & 1 & 0 & 0 & 1 & 1 & 1 & 1 \\
\hline T3 & 1 & 1 & 0 & 0 & 1 & 1 & 1 & 1 \\
\hline $\mathrm{T} 4$ & 1 & 1 & 0 & 0 & 0 & 0 & 0 & 0 \\
\hline T5 & 1 & 1 & 0 & 0 & 0 & 0 & 0 & 0 \\
\hline T6 & 1 & 1 & 0 & 0 & 0 & 0 & 0 & 0 \\
\hline $\mathrm{T} 7$ & 1 & 1 & 0 & 0 & 0 & 0 & 0 & 0 \\
\hline $\mathrm{T} 8$ & 1 & 1 & 0 & 0 & 0 & 0 & 0 & 0 \\
\hline T9 onwards & 0 & 0 & 0 & 0 & 0 & 0 & 0 & 0 \\
\hline $\begin{array}{l}\text { Voluntary anal } \\
\text { contraction }\end{array}$ & No & & No & & No & & No & \\
\hline $\begin{array}{l}\text { Bladder and } \\
\text { bowel sensation }\end{array}$ & No & & No & & No & & No & \\
\hline $\begin{array}{l}\text { Upper motor } \\
\text { neurone signs }\end{array}$ & Yes & & No & & No & & No & \\
\hline
\end{tabular}

Upper motor neurone signs (brisk deep tendon reflexes and extensor Babinski reflex) are also included to indicate the nature of paralysis. Post-operative improvement in neurological status has been highlighted (in bold)

upper back, 2 day history of paralysis in all four limbs, and 1 day history of loss of voluntary control of micturition. Examination revealed tenderness at the cervico-thoracic

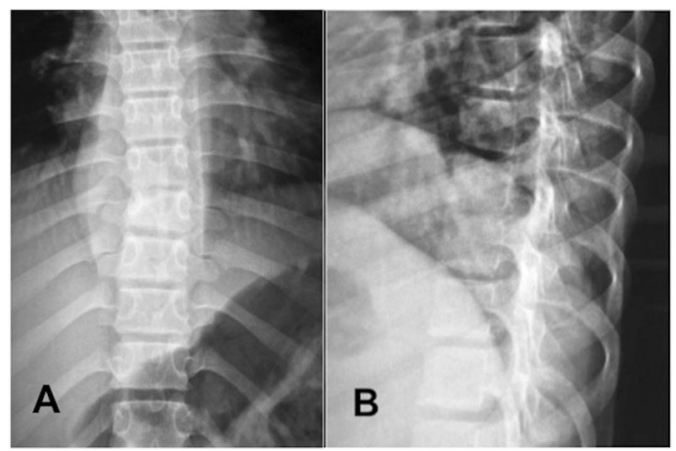

Fig. 1 Antero-posterior view (a) of mid-thoracic spine showing a fusiform right-sided paravertebral abscess shadow with maximum width at T7-8 level. Lateral view (b) of mid-thoracic spine showing decreased intervertebral disc space between T7-8 vertebrae

junction and T7-8 spinous processes. Bilateral strength in the $\mathrm{C} 7$ and $\mathrm{T} 1$ muscle groups was $0 / 5$ while lower extremity strength was $2 / 5$ throughout. Light touch and pin prick sensations were diminished in the $\mathrm{C} 7$ to $\mathrm{T} 8$ distribution and were absent below. Knee reflexes were brisk and Babinski sign was positive. She did not have voluntary bladder and bowel control. (Detailed neurological charting is given in Table 1.)

Radiographs of the thoracic spine revealed a decrease in the height of T7-8 intervertebral disc and a paravertebral soft tissue shadow at the same level (Fig. 1). However, radiographs of the cervical spine did not show any bony or soft tissue abnormalities. Magnetic resonance imaging (MRI) of the spine showed compression of the spinal cord by a posterior epidural abscess originating from the T7-8 level and extending up to the $\mathrm{C} 4$ level, with mild reduction in the height of the T7-8 intervertebral disc (Fig. 2).

Based on this clinical presentation and supported by the available radiological evidence, we made a diagnosis of infective spondylodiskitis at T7-8 vertebral level, with rapid onset neurological deficit due to an epidural abscess. Given the patients' socio-economic background, we suspected the pathology to be tuberculosis.

To decompress the epidural abscess, a right-sided hemilaminectomy was performed at C7 and T7. Approximately $8 \mathrm{~mL}$ of thick white pus was drained from the epidural space and sent for microbiological analysis. To intraoperatively confirm the adequacy of decompression, a $10 \mathrm{~F}$ silastic catheter was passed proximally into the epidural space from the T7 level. Cartridge based nucleic acid amplification test (CBNAAT) of the pus confirmed the presence of Mycobacterium tuberculosis. CBNAAT also revealed that the organism was sensitive to Rifampicin. Based on this result anti-tubercular therapy as per the national tuberculosis guidelines were started (Rifampicin $15 \mathrm{mg} / \mathrm{kg} /$ day, Isoniazid $10 \mathrm{mg} / \mathrm{kg} /$ day, Pyrazinamide $30 \mathrm{mg} / \mathrm{kg} / \mathrm{day}$, Ethambutol $20 \mathrm{mg} / \mathrm{kg} / \mathrm{day}$, and intramuscular 


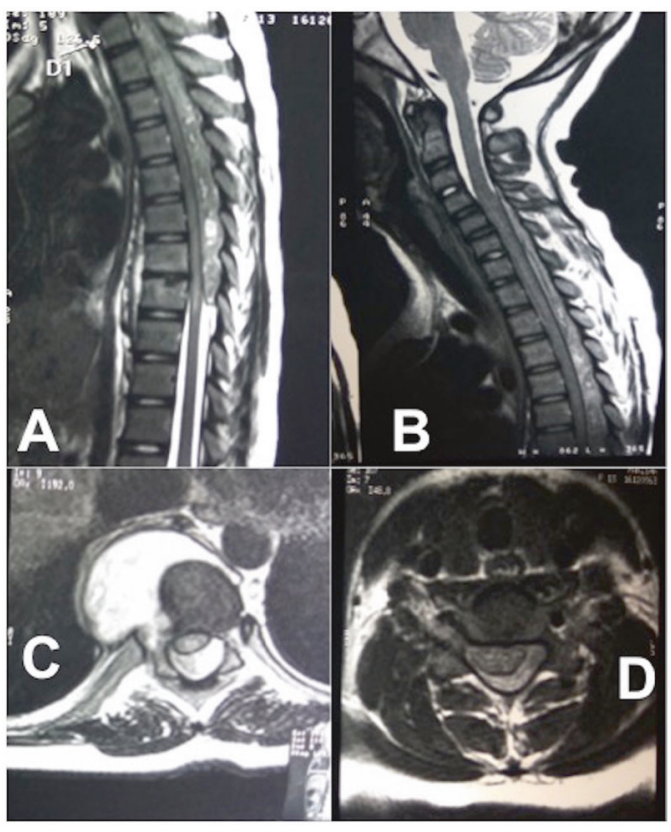

Fig. 2 a T2-weighted sagittal section of thoracic spine showing posterior epidural collection from T8 upwards, mild decrease in height of T7-8 intervertebral disc, and an anterior sub-ligamentous collection at the same level. b T2-weighted sagittal section of cervical spine showing proximal extent of epidural collection up to C4. c Axial T2weighted image showing predominantly right sided paravertebral hyperintense abscess with extension into posterior epidural space leading to compression of the spinal cord. d Axial T2-weighted image of cervical spine showing compression of the cervical spinal cord by a posterior iso-intense epidural collection

injection of streptomycin $0.75 \mathrm{~g} /$ day) and she was advised absolute bed rest [5].

Around $12 \mathrm{~h}$ after the surgery, a detailed neurological examination was conducted and the patient was found to have complete flaccid quadriplegia from C7 onwards (Table $1)$.

On the third post-operative day she recovered partial motor power in muscles supplied by $\mathrm{C} 6$ and $\mathrm{C} 7$, on the left side (Table 1). She was also able to localize fine touch between C6 to T3 but complete sensory loss from T4 onwards persisted. There was no further neurological improvement. The sudden post-operative neurological deterioration and lack of further neurological recovery prompted us to repeat an MRI at 3 weeks (Fig. 3). The MRI confirmed that hemilaminectomy had been performed at the intended levels (C7 and T7). Comparison with the preoperative MRI also showed partial resolution of abscess at the mid-thoracic level (T5-7), although, abscess/granulation tissue persisted in the posterior epidural space from C4-T4 levels. A syrinx had developed in the spinal cord at vertebral level of T5-9 (most prominent at T5-6). At the level of the syrinx, the spinal cord was seen in axial sections to be lying freely, without any external compression. The cord

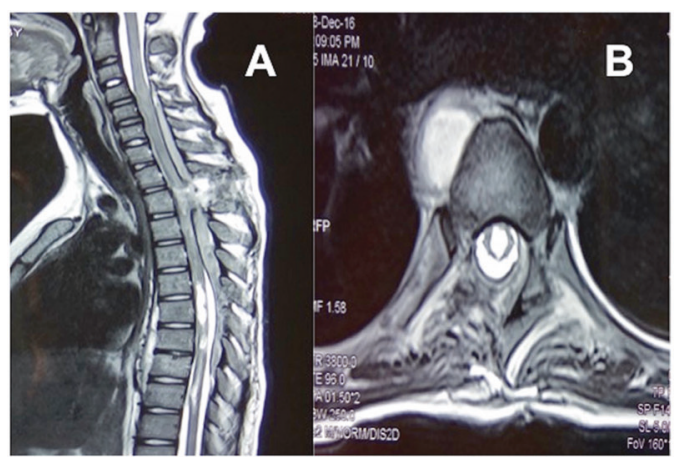

Fig. 3 a T2-weighted mid sagittal section showing syrinx formation at T5-6, T7, and T9 levels. Post-surgery signal intensity changes seen at T1-2 level. Decrease in posterior epidural collection from T5-8 levels, but persisting proximally. b T2-weighted axial section showing severe dilatation of central canal of spinal cord and thinning of spinal parenchyma

parenchyma, however, was thinned out and the central canal was dilated.

The patient was allowed to mobilize on a wheelchair with a Taylor's brace at 6 weeks. Family members were trained to do passive stretching exercises and assisted exercises to prevent development of contractures and maintain motor strength. They were also educated prevention of pressure sores. Intermittent clamping of urinary catheter was done and catheter was changed every 3 weeks. Streptomycin and Pyrazinamide were withdrawn at 2 and 3 months respectively. At one-year follow up, there were no constitutional symptoms or spinal tenderness. Erythrocyte sedimentation rate was within normal limits. All antitubercular drugs were stopped based on these clinical and laboratory parameters, in spite of the patient not showing any signs of further neurological recovery. Two years postoperatively, there has been no recurrence of tuberculosis and also no change in the neurological status (Table 1). Patient was still wheelchair bound and dependent on family members for activities of daily living.

\section{Discussion}

Syringomyelia is a fluid-filled dilation of the central canal of the spinal cord. This is commonly caused by Arnold-Chiari malformation, meningitis, intra-medullary tumors, spinal trauma and irradiation [6]. Rarely, it has been reported to occur with tubercular meningitis or intradural tubercular granuloma $[7,8]$.

Syrinx formation in tuberculosis can occur by two mechanisms [9-11]. The ischemic hypothesis proposes that obliterative endarteritis caused by tuberculosis can lead to softening of the damaged spinal cord parenchyma. The other hypothesis proposes that meningeal scarring can 
obstruct flow of cerebro-spinal fluid and this can lead to syrinx formation.

Post-operative syringomyelia in tuberculosis has been reported twice $[12,13]$. However, in both of these cases the cause was attributed to a pre-existing intradural-extramedullary tuberculoma with concurrent arachnoiditis. Moon et al. [3] in one of the largest studies on surgery-related complications of spinal tuberculosis did not report a single case of post-operative syrinx formation.

In this case, we do not attribute syrinx formation to either arachnoiditis or intradural tuberculoma since there were no relevant clinical or radiological signs. We also do not believe that vascular insult to the cord during the surgery precipitated syrinx formation, since hemilaminectomy at C7 and T7 was unlikely to disturb any of the segmental vessels supplying the spinal cord and we also did not encounter any major intra-operative bleeding.

We propose "epidural compartment syndrome" as the cause of syrinx formation in this case. The epidural space, though continuous from the base of the skull to the sacrococcygeal membrane, has been demonstrated to be segmental [14]. Axially the epidural space is bound by the vertebral ring comprising of vertebral body, pedicles, laminae, and spinous process. Thus, it can behave as a closed compartment if the vertebral ring is intact. Epidural analgesic infusion has been known to cause epidural compartment syndrome which led to neurological deficit and necessitated urgent surgical decompression [15]. Any rapid accumulation of fluid in the epidural space can hence lead to such a clinical scenario.

Tuberculosis of the spine is a slowly progressive disease; hence, the accumulation of pus occurs in tandem with bony destruction. Osseous destruction breaks the closed vertebral ring around the epidural space and gives the tubercular abscess an opportunity to track elsewhere. This would prevent the development of epidural compartment syndrome in spinal tuberculosis. Neurological deficit would then occur due to mechanical pressure from bony debris, caseous granulation tissue, sequestered intervertebral disc, and/or pathological dislocation [16].

We hypothesize that in our case, the epidural abscess developed acutely (patient presented to us within 2 days of onset of weakness), even before significant vertebral destruction had occurred (as is evident on the pre-operative radiographs and $\mathrm{MRI}$ ). This abscess was trapped within the cervico-thoracic vertebral canal, thus leading to an increase in the epidural compartment pressure and compromise of the spinal cord microcirculation. Ischemia of the spinal cord parenchyma led to necrosis and softening. When the epidural pressure was released by surgical decompression, it allowed the central canal to dilate and form a syrinx.

Syringo-peritoneal shunt [13, 17] and arachnoid dissection with duraplasty [18] have been tried with moderate success for surgical management of syringomyelia. However, multiple authors have reported high failure rate and poor long-term results of surgical treatment of arachnoiditisassociated syringomyelia [19-21]. Conservative treatment by steroids along with anti-tubercular therapy has been shown to produce neurological recovery in such patients $[22,23]$. Proponents of conservative treatment argue that the presence of arachnoiditis at different spinal levels makes the outcome of surgery hard to predict and unreliable. We did not give steroids to this patient since the syrinx was discovered 3 weeks after the surgery and there was no associated arachnoiditis. Surgical creation of a syringoperitoneal shunt was offered, but the patient was unwilling to undergo another surgical procedure.

Ours was a case of T7-8 tubercular spondylodiskitis with epidural abscess extending up to $\mathrm{C} 4$ for which dual level spinal decompression was done. In spite of adequate decompression, the patient deteriorated neurologically. Microbiological analysis of the pus sample found the mycobacterium to be sensitive to all the first-line antitubercular drugs, hence ruling out the possibility of a drug-resistant organism as a cause of neurological deterioration. Post-operative MRI revealed multi-level syrinx formation from T5-9. We associated this to be the cause of complete neurological deficit from T4 below. We attribute the formation of syrinx in this case to an "epidural compartment syndrome" caused by an acute epidural abscess. This case highlights the possibility of syringomyelia as a cause of post-surgical neurological deterioration in spinal tuberculosis. Spine surgeons also need to be aware of epidural compartment syndrome as a clinical entity and its consequences if not decompressed urgently.

Author contribution Author YK was the chief resident of the ward where the patient concerned was admitted. The chief operating surgeon was author NB, while authors PL and AK were his surgical assistants. They were responsible for preparation of the manuscript. Final proof reading and editing of the manuscript was done by NB and YK. The manuscript has been read and approved by all the authors and requirement for authorship of this document has been met. Each author believes that the manuscript represents honest work.

\section{Compliance with ethical standards}

Conflict of interest The authors declare that they have no conflict of interest.

Informed consent A written informed consent was obtained from the patients' legal guardians authorizing radiological examination, photographic documentation, and treatment. They were also informed that the data concerning the case would be submitted for publication and they consented.

Publisher's note: Springer Nature remains neutral with regard to jurisdictional claims in published maps and institutional affiliations. 


\section{References}

1. World Health Organization. The end TB strategy. 2015. https://www.who.int/tb/strategy/End_TB_Strategy.pdf?ua=1

2. Tuli SM. Tuberculosis of the skeletal system. 3rd ed. New Delhi: Jaypee Brothers; 2004

3. Moon MS, Kim SS, Moon YW, Moon H, Kim SS. Surgeryrelated complications and sequelae in management of tuberculosis of spine. Asian Spine J. 2014;8:435-45.

4. Roberts TT, Leonard GR, Cepela DJ. Classifications in brief: American Spinal Injury Association (ASIA) Impairment Scale. Clin Orthop Relat Res. 2016;475:1499-504.

5. Central Tuberculosis Division, Government of India. Treatment of TB. Technical and operational guidelines for TB control in India. 2016. p. 30-44.

6. Rai SKR, Rai PSK. Volume change theory for syringomyelia: a new perspective. Asian J Neurosurg. 2015;10:245-51.

7. Muthukumar N, Sureshkumar V. Concurrent syringomyelia and intradural extramedullary tuberculoma as late complications of tuberculous meningitis. J Clin Neurosci. 2007;14:1225-30.

8. Garg RK, Malhotra HS, Gupta R. Spinal cord involvement in tuberculous meningitis. Spinal Cord. 2015;53:649-57.

9. Chang HS, Nakagawa H. Theoretical analysis of the pathophysiology of syringomyelia associated with adhesive arachnoiditis. J Neurol Neurosurg Psychiatry. 2004;75:754-7.

10. Hui AC, Chan YL, Kay R. Syrinx and tuberculoma formation in tuberculous arachnoiditis. Can J Neurol Sci. 2001;28:148-9.

11. Caplan LR, Norohna AB, Amico LL. Syringomyelia and arachnoiditis. J Neurol Neurosurg Psychiatry. 1990;53:106-13.

12. Jeong DK, Kwon YM. Intradural extramedullary tuberculoma of the spinal cord following tuberculous meningitis. Korean J Spine. 2015;12:107-10.

13. Gul S, Celebı G, Kalayci M, Acikgoz B. Syringomyelia and intradural extramedullary tuberculoma of the spinal cord as a late complication of tuberculous meningitis. Turk Neurosurg. 2010;20:561-5.

14. Hogan QH. Lumbar epidural anatomy. A new look by cryomicrotome section. Anesthesiology. 1991;75:767-75.

15. Sibell DM, Murphy M, Mayberry J. Thoracic epidural infusion complicated by epidural compartment syndrome. Anesthesiology. 2003;98:788-90.

16. Jain AK, Jena A, Dhammi IK. Correlation of clinical course with magnetic resonance imaging in tuberculous myelopathy. Neurol India. 2000;48:132-9.

17. Cacciola F, Capozza M, Perrini P, Benedetto N, Di Lorenzo N. Syringopleural shunt as a rescue procedure in patients with syringomyelia refractory to restoration of cerebrospinal fluid flow. Neurosurgery. 2009;65:471-6.

18. Klekamp J. Treatment of syringomyelia related to nontraumatic arachnoid pathologies of the spinal canal. Neurosurgery. 2013;72:376-89.

19. Klekamp J, Batzdorf U, Samii M, Bothe HW. Treatment of syringomyelia associated with arachnoid scarring caused by arachnoiditis or trauma. J Neurosurg. 1997;86:233-40.

20. Koyanagi I, Iwasaki Y, Hida K, Houkin K. Clinical features and pathomechanisms of syringomyelia associated with spinal arachnoiditis. Surg Neurol. 2005;63:350-5.

21. Kaynar MY, Koçer N, Gençosmanoğlu BE, Hanci M. Syringomyelia - as a late complication of tuberculous meningitis. Acta Neurochir (Wien). 2000;142:935-8.

22. Jawad N, Jafri S, Naqvi S, Ahmad SM, Naveed S, Ali Z. A case report on complicated tuberculous meningitis. Cureus. 2017;9: e1222

23. Sharma B, Nagpal K, Handa R, Gupta P. Intradural extramedullary and intracranial tuberculomas with concurrent communicating syringomyelia. BMJ Case Rep. 2014. https://doi.org/ 10.1136/bcr-2013-201368. 